\title{
Validação da Escala de Julgamento e Significado do Produto
}

\author{
Marcelo Vinhal Nepomuceno \\ Cláudio V. Torres \\ Universidade de Brasília
}

\begin{abstract}
Resumo
O significado que um produto tem para o consumidor - considerado como simbólico ou utilitário - e o julgamento que o indivíduo realiza para avaliar o significado do produto têm sido variáveis estudadas na predição do comportamento de compra. O objetivo deste estudo foi verificar a fidedignidade e confiabilidade do modelo teórico proposto por Allen (1997), através da tradução e validação da Escala de Significado e Julgamento do Produto. A amostra foi composta de 588 participantes, possuindo uma boa distribuição demográfica entre sexos e idade. Os resultados desta pesquisa indicaram dois fatores: Julgamento e Significado Racional (variância explicada de 18,33; alfa de 0,76) e Julgamento e Significado Emotivo (variância explicada de 15,97; alfa de 0,73). Após as análises, todos os 19 itens iniciais permaneceram na escala. Os dados encontrados indicam a necessidade de adaptação e melhoria da escala para a realidade nacional. Aparentemente, a contradição encontrada entre o modelo proposto por Allen (1997) e os resultados advêm de problemas psicométricos da escala, o que sugere a necessidade de novas pesquisas para confirmação dessa possibilidade.

Palavras-chave: comportamento de compra; significado do produto; julgamento do produto; validação de escala
\end{abstract}

\begin{abstract}
Validation of the Scale of Judgment and Meaning of the Product. The meaning that a product has for the consumer - which can be considered as symbolic or utilitarian - and the judgment made by an individual to evaluate the product meaning are both variables that have been studied to predict the buying behavior. The objective of this study was to verify the reliability of the model proposed by Allen (1997), through the translation and validation of the Scale of Judgment and Meaning of the Product. The study sample was composed by 588 participants, with a good distribution between sex and age. Results indicated the presence of two factors: Rational Judgment and Meaning (18.33\% of explained variance, with alpha of 0.76) and Emotional Judgment and Meaning (15.97\% of explained variance, with alpha of 0.73 ). After the analysis, all 19 original items of the scale were retained. The obtained data indicated the need for adaptation and enhancement of the scale to the national reality. Apparently, the contradiction between the model proposed by Allen (1997) and results found in this study reveals psychometric problems of the scale, suggesting the need for new studies to confirm this possibility.
\end{abstract}

Keywords: buying behavior; product meaning; product judgment; scale validation

$\mathrm{E}$ vidências têm demonstrado a relevância de se estudar o comportamento do consumidor em Ciências Sociais. O fato de o consumo de bens e serviços fazer parte do nosso dia-a-dia tem suscitado o desenvolvimento de teorias e modelos na Economia (Weber, 1922/1991), Sociologia (Marx, 1844/2003), Administração e Marketing (Engel, Blackwell, \& Miniard, 2000; Kotler, 1984) e, mais recentemente, na Psicologia (Kahle \& Kennedy, 1988). Com esta preocupação, Allen e Ng (1999) e Allen (2000) propuseram um modelo que busca explicar a influência dos valores básicos (Schwartz \& Bilsky, 1987, 1990; Tamayo \& Schwartz, 1993) na escolha de produtos pelos consumidores. No modelo de duas rotas, Allen (1997; 2000; 2001) parte da pressuposição básica que a escolha e seleção de um produto ou serviço é predita pelo significado atribuído a este. Para medir tais significados e formas de julgamento, Allen (2001) propôs um instrumento, a Escala de Julgamento e Significado do Produto. O objetivo do presente estudo foi o de testar a validade, examinar sua estrutura teórica e investigar a aplicabilidade do instrumento em uma realidade brasileira, especificamente, com residentes da cidade de Brasília (Distrito Federal).

\section{Atribuição de significado}

A atribuição de significado é um processo psicológico corriqueiro e relevante para as mais variadas atividades e relações humanas. As pessoas atribuem um significado a cada 
evento, a cada objeto, a cada pertence, a cada pessoa e a cada palavra. Segundo a semiótica (Allen, 2000), a decodificação do significado de um gesto pode ser essencial para compreender a reação ou comportamento de um indivíduo. Logo, é possível pensar que o significado que um consumidor atribui a um produto serve como base importante para compreender seu comportamento de compra.

Segundo levantamento bibliográfico realizado por Richins (1994), o significado resulta do processo de interpretação de estímulos externos. Assim, ele é compreendido como uma percepção subjetiva ou reação afetiva de uma pessoa frente a um objeto. Essas percepções e reações se constituem e são influenciadas por relações interpessoais e sociais. O significado é o resultado da influência de ambas as relações (sociais e interpessoais) sobre a interpretação dada ao objeto. Logo, significados individuais podem ser contrários aos sociais devido à subjetividade de cada indivíduo no processo de interpretação.

Richins (1994) considera ainda que nem sempre o valor monetário do produto está diretamente relacionado com o seu significado. Neste sentido, o valor atribuído ao produto por um indivíduo é, na verdade, mais do que o seu valor monetário, o seu valor simbólico. Essa realidade desafia noções tradicionais da Economia como a do valor de troca (Weber, 1922/1991; Marx, 1844/2003), que pressupõem um elemento comum a todas as mercadorias, como o dispêndio de tempo para a sua produção. Contrariamente, o significado de um produto é particular a cada pessoa, o que faz com que os indivíduos atuem, na realidade, na tentativa de maximizar o valor deste produto (Thaler, 1985). Outra pressuposição da Economia que é desafiada pelo valor simbólico de um produto é a chamada Lei da Oferta e Demanda. Segundo Richins (1994), a subjetividade de cada pessoa advinda de sua história de vida faz com que um determinado produto possua um valor incoerente às regras de mercado. Tal incoerência pode ser utilizada para explicar, por exemplo, a lealdade a determinados produtos, independente da sua oferta no mercado. Outro exemplo do valor simbólico de um produto pode ser observado no valor atribuído por um pai de família à casa na qual seus filhos foram educados e criados. A diferença entre o valor subjetivo e valor monetário demonstra não apenas a complexidade do tema, mas também as diversas implicações práticas desse fato. Torna-se essencial, assim, o conhecimento do significado real de um produto ou serviço para seu público alvo, já que ele influenciará seu valor monetário final e também sua viabilidade mercadológica.

O significado pode possuir duas naturezas (Richins, 1994). A primeira é o significado público, definido como "o significado subjetivo dirigido a um objeto por observadores externos” (p. 505). Para que seja público, o significado deve ser comum aos observadores. A segunda natureza é o significado particular, definido como "a soma do significado subjetivo que um objeto detém para um indivíduo em particular" (p. 506). Vale notar que o significado particular pode ser influenciado pelo público e vice-versa.

Outro fato que deve ser considerado, quando se discute o significado atribuído pelas pessoas, relaciona-se à impor- tância das posses como um fator relevante sobre a definição do self e criação de um senso de identidade. William James (1890), um dos precursores da Psicologia, já apontava para a importância da posse como elemento formador do self:

Está claro que entre o eu dito por uma pessoa e o meu há uma linha difícil de traçar. (...) O self de um homem é a soma total de tudo aquilo que ele pode chamar de seu, não apenas seu corpo e capacidades físicas, mas suas roupas e casa, esposa e filhos, ancestrais e amigos, reputação e trabalho, terras, barcos e contas bancárias. (p. 291, grifo nosso)

Outros autores, como Richins (1994), Belk (1988) e Tamayo (1981), também discutem e apontam a relevância e influência que as posses geram no desenvolvimento da identidade e no autoconceito de um indivíduo. Tamayo (1981) resume: “o autoconceito é um conjunto de percepções de si mesmo. O conteúdo dessas percepções é tudo aquilo que o indivíduo reconhece como fazendo parte de si” (p. 89). McCracken (1987), por meio de seu estudo sobre o papel das posses para facilitar momentos de transição, também sugere que as posses podem servir de instrumento para manter o autoconceito.

Tendo em vista a influência da posse sobre o self $\mathrm{e}$ autoconceito, é coerente imaginar que o significado que as pessoas atribuem ao que possuem não apenas diz algo sobre elas mesmas, mas também pode servir como base para aquilo que desejam adquirir. Logo, o significado atribuído é não apenas descritivo, mas prescritivo do comportamento de compra. Além disso, a compreensão do significado atribuído aos mais diversos produtos é bastante relevante, pois é esperado que o mesmo influencie na escolha do que será adquirido e, por conseguinte, no self do indivíduo. Ou seja, não é apenas o consumidor que modela o produto, mas também ele é modelado por aquilo que consome.

No presente trabalho, o significado é entendido como a percepção subjetiva ou reação afetiva de um indivíduo perante um objeto (Richins, 1994). Tal definição pode levar a uma confusão conceitual entre o significado de um produto e a atitude perante esse mesmo produto, uma vez que o significado pode ser compreendido como uma relação, positiva ou negativa, entre uma pessoa e um objeto. Vale lembrar que, como aponta Heider (1967), atitude é uma relação positiva ou negativa entre pessoas ou entre uma pessoa e um objeto, situação, evento, idéia, etc. Logo, assim como no caso das atitudes, é possível que as pessoas atribuam um significado a um produto, mesmo nunca tendo entrado em contato com o mesmo. Sendo assim, para que um produto tenha um significado para uma pessoa, basta apenas que ela tenha escutado algo sobre o mesmo ou ao menos compreenda o conceito do produto em questão.

Tendo sido apresentadas estas definições, torna-se mais compreensível observar as relações entre atitudes e significado de um produto. Em resumo, pode-se dizer que o significado atribuído a um produto ou serviço é o resultado das emoções ou sentimentos (componente afetivo) que a pessoa obteve a partir da experiência com o objeto (produto ou serviço). Esta experiência é mediada pelas informações e conhecimentos (componente cognitivo) prévios ao contato com o 
objeto e que geram uma probabilidade de reação, positiva ou negativa, frente ao mesmo (componente conativo). Contudo, vale lembrar que, em uma hierarquia cognitiva, o significado é superior à atitude, uma vez que ele se encontra mais próximo aos valores humanos do que a atitude (Allen, 1997). Poderíamos resumir a diferença entre os dois conceitos quando entendemos o significado como algo mais abstrato e a atitude como mais palpável e próxima da intenção comportamental.

Diversos teóricos (e.g., Fishbein, 1963; Healey, Lutz, \& Healey, 1974; Pratkanis, Breckler, \& Greenwald, 1989) discutiram sobre as funções das atitudes. Locander e Spivey (1978) realizaram uma aprofundada revisão de literatura sobre o tema e identificaram como a melhor descrição das funções da atitude aquelas já descritas anteriormente por Katz (1960). Este autor encontrou quatro funções: a defesa do ego, sendo utilizado como um mecanismo para ajustar ou impedir dificuldades internas e externas; expressão de um valor, ajudando o indivíduo a expressar de forma positiva seus valores pessoais mais importantes ou autoconceito; conhecer o ambiente, atuando de forma a organizar o ambiente, compreendendo os fenômenos e integrando-os de forma coerente; e utilitária ou adaptativa, sendo instrumento para alcançar um determinado objetivo, maximizando os prêmios e minimizando as penas.

Considerando ainda as funções da atitude, o significado de um produto pode ser o resultado da expressão de um valor (através da atribuição de significado de acordo com seus valores pessoais) ou ainda uma forma de organizar o ambiente (atribuindo o significado de acordo com as experiências de vida, organizando assim o significado de cada produto com que teve contato). Richins (1994) propôs quatro categorias de significado: valor utilitário, de entretenimento, representante de laços interpessoais, identidade e auto-expressão. Allen (1997) observou que essas quatro categorias se aglutinam em duas categorias mais abrangentes, isto é, o significado utilitário e o simbólico.

Para Allen e Ng (1999), o significado simbólico é subjetivo e está relacionado ao lado afetivo e crenças abstratas do indivíduo. Ele é baseado em atributos externos ao objeto em questão, sendo formado também pelo contexto social e cultural. Diferentemente, o significado utilitário é objetivo e está baseado em atributos tangíveis do produto, ou seja, relaciona-se à sua utilidade, conveniência, eficiência ou mesmo ao seu valor como moeda de troca. Os autores sugerem ainda que os valores humanos básicos podem influenciar a preferência por produtos, por meio da mediação dos significados utilitários ou simbólicos atribuídos ao produto.

Para explicar a influência dos valores na preferência por significado simbólico ou utilitário, Allen (1997) propôs um modelo que não se limita apenas a analisar a importância do significado sobre o comportamento do consumidor. Seu modelo considera também a influência do tipo de julgamento que o indivíduo faz sobre o processo de decisão de compra e preferência de produtos. Segundo Allen, esse julgamento se divide entre o julgamento afetivo ou o julgamento passo-apasso.

\section{Relação julgamento-significado}

Mittal (1988) reforçou a importância do modo afetivo de escolha como processo relevante na formação da preferência de um determinado produto ou serviço. Este julgamento possui três características principais: é holístico, é influenciado pelo self do indivíduo e é difícil de explicar. A primeira diz respeito à inadequação dos estímulos reais (discriminação, reconhecimento e categorização de objetos e eventos) para avaliar os objetos. O modo afetivo de escolha é influenciado pelo self do indivíduo, uma vez que ele não considera apenas as características objetivas do objeto, mas também demonstra algo de nós mesmos, ou seja, é um julgamento que está focado na própria pessoa. A última característica pode ser explicada pela natural dificuldade de verbalização de processos tidos como internos. Isso leva a verbalizações tidas como reações ao objeto e não explicação dos motivos. Logo, o julgamento afetivo não está ligado exclusivamente às características do objeto, mas também às características da pessoa.

Outro processo descrito por Mittal (1988) diz respeito ao modo de processamento informacional, que está baseado na avaliação dos atributos tangíveis e funções utilitárias de um determinado produto. Segundo Mittal, este tipo de julgamento explica a escolha do consumidor em termos cognitivos. Nele, o consumidor adquire informações sobre atributos de um produto, forma um critério avaliativo, julga os critérios em vários níveis e aplica uma regra ou heurística para realizar uma avaliação geral. Para este tipo de julgamento o consumidor é encarado como um computador.

Allen (1997) uniu as proposições de Mittal (1988) com a idéia defendida por Fiske e Pavelchak (1986, citado por Allen \& Ng, 1999), a respeito das avaliações no momento da escolha de um objeto. Segundo Fiske e Pavelchak, os indivíduos podem dar uma resposta afetiva passo-a-passo (i.e., a atitude com relação ao objeto é resultado de uma combinação algébrica do afeto associado a cada atributo), ou uma resposta afetiva baseada na categoria do produto (i.e., o objeto é comparado ao seu exemplar e, quando são compatíveis, os afetos associados ao exemplar é transferido para o objeto, “gestáltica”). Allen (1997) e de Allen e Ng (1999) propuseram a existência de dois tipos de julgamento. Um chamado de passo-a-passo, que se relaciona ao modo de processamento informacional de Mittal e à resposta afetiva passo-a-passo, descrita por Fiske e Pavelchak (1986), e outro chamado de julgamento afetivo, relacionado ao modo afetivo de escolha (Mittal, 1988) e à resposta afetiva baseada na categoria do produto (Allen \& Ng, 1999).

Tais conceitos - significado, tipo de julgamento e preferência por produtos - foram integrados por Allen (1997; 2000; 2001) no modelo de duas rotas. Este modelo procura explicar a influência dos valores humanos sobre a tomada de decisão dos consumidores, seja por meio de sua influência sobre o tipo de julgamento realizado, ou sobre o significado de um produto. Segundo Allen e Ng (1999), o significado utilitário localiza-se nos atributos tangíveis do produto, por exemplo, a conexão de um computador à internet, a velocidade do processador, a capacidade de memória, etc. Tais atributos, 
unidos, definiriam o significado utilitário de um computador, para Allen e Ng. Logo, o significado utilitário de um produto exige que seu julgamento seja feito de forma racional e objetiva caracterizando assim o julgamento passo-a-passo, descrito acima.

Ainda segundo Allen e Ng (1999), o significado simbólico está diretamente ligado aos valores pessoais dos indivíduos, uma vez que ele é composto por crenças subjetivas, associadas a um objeto ou a uma ação. Por exemplo, marcas procuram simbolizar algo para chamar a atenção de seus consumidores. Uma pode simbolizar aventura e prazer em dirigir; outra pode simbolizar o compromisso de menor preço, e assim por diante. São, em geral, baseados em crenças subjetivas e representam valores pessoais que podem, ou não, ser importantes aos consumidores. Segundo os autores, para que este tipo de significado seja formado, é necessário um julgamento baseado em afeto e intuição.

A Figura 1 apresenta o modelo proposto por Allen (2000, 2001). Segundo o autor, os valores humanos podem influenciar diretamente o significado simbólico de um produto por meio do julgamento afetivo e influenciar indiretamente o significado utilitário por meio do julgamento passo-a-passo.

Como pode ser observado na Figura 1, Allen propõe que os valores humanos básicos (Schwartz \& Bilsky, 1987, 1990) podem predizer a preferência por um determinado produto por duas rotas distintas. Valores podem predizer diretamente a preferência pelo produto ao predizer a preferência pelo significado simbólico do mesmo. Neste sentido, o consumidor estaria fazendo um julgamento afetivo dos atributos intangíveis do produto. Os valores também podem predizer a preferência de um produto ao predizer o significado utilitário do produto, fazendo assim um julgamento passo-a-passo sobre os atributos tangíveis deste. Para medir a relação entre os valores e a rota utilizada para se julgar o produto, Allen (1997) propôs uma escala que busca avaliar o tipo de julgamento (passo-a-passo e afetivo) e significado atribuído ao produto pelo consumidor.

A versão original do instrumento de Allen (1997) possui 19 itens totalizando quatro fatores. São eles: Julgamento Afetivo (5 itens); Julgamento Passo-a-passo (6 itens); Significado Simbólico (6 itens); e Significado Utilitário (2 itens). Em suas primeiras aplicações no Brasil (Nepomuceno \& Torres, 2003; Torres \& Allen, no prelo), o instrumento foi traduzido e retraduzido em duas versões por especialistas diferentes. Em seguida uma única versão foi elaborada, sendo escolhidos os itens com redação mais clara e objetiva. A escala passou então pelo teste interjuízes, sendo verificada também a qualidade da tradução. Finalmente, Nepomuceno e Torres (2003) também realizaram uma análise fatorial e encontraram alfas de 0,75 (Julgamento e Significado Racional) e 0,78 (Julgamento e Significado Emotivo). A Tabela 1 mostra a redação original de cada item e sua versão traduzida.

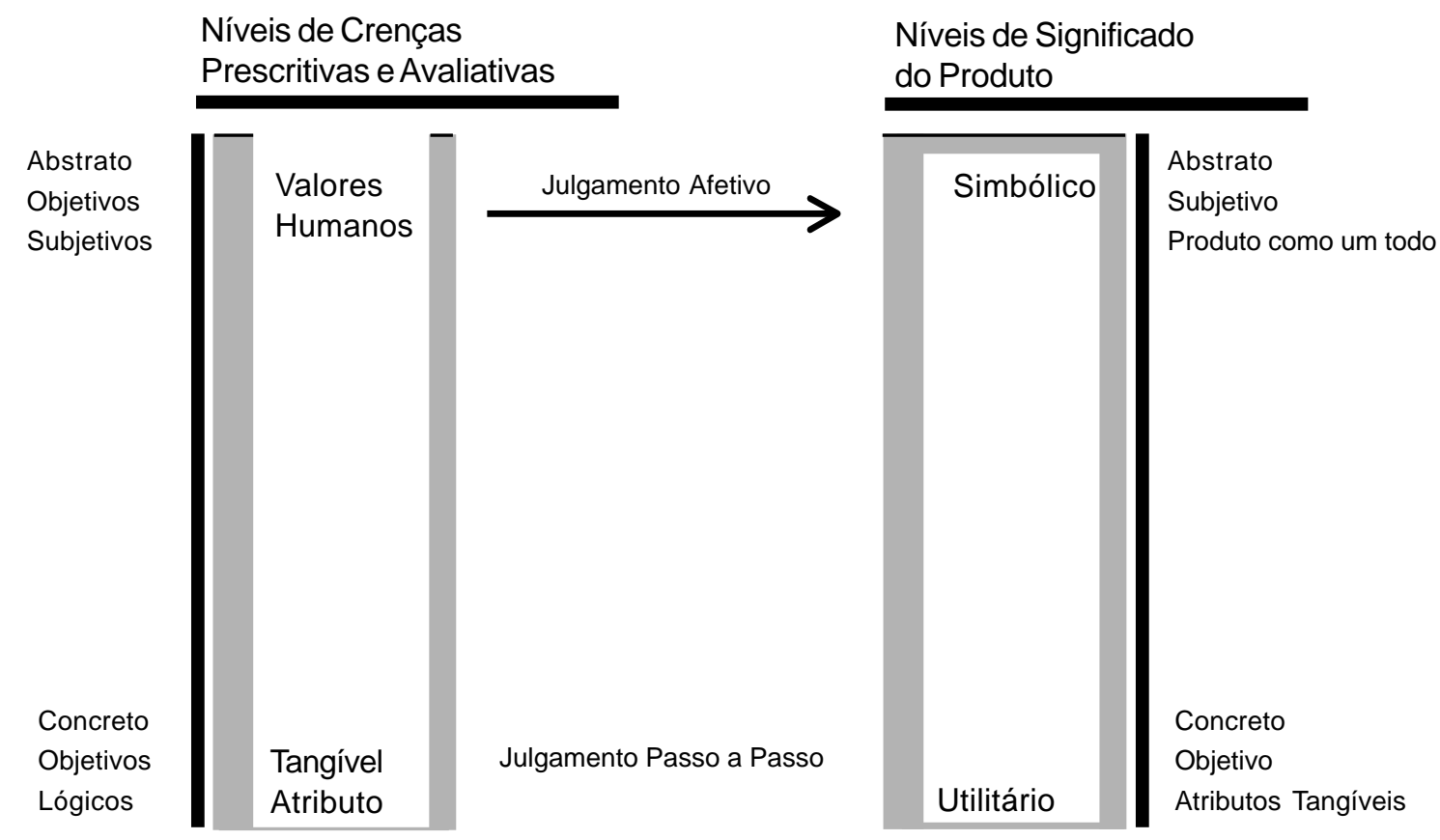

Rota Indireta

Rota Direta

Figura 1. Modelo de Multi-Atributos, de Allen (1997) 
Tabela 1

Itens na redação original, na versão traduzida e fatores ao qual estavam associados

\begin{tabular}{|c|c|c|}
\hline Redação Original (Inglês) & Redação em Português & $\begin{array}{l}\text { Fator - Versã̃o } \\
\text { Original }\end{array}$ \\
\hline $\begin{array}{l}1 \text { - I belive in Being logical and rational, when } \\
\text { deciding on a product }\end{array}$ & $\begin{array}{l}\text { 1- Eu acredito em ser lógico e racional quando } \\
\text { decido sobre um produto. }\end{array}$ & $\begin{array}{l}\text { Julgamento Passo a } \\
\text { Passo }\end{array}$ \\
\hline $\begin{array}{l}2 \text { - Before you make your final selection of a } \\
\text { product, you would: Consider the pros and } \\
\text { consfor each product }\end{array}$ & $\begin{array}{l}2 \text { - A ntes de você tomar a decisão final sob re um } \\
\text { produto, você: Considera os prós e contras sobre } \\
\text { cada produto. }\end{array}$ & $\begin{array}{l}\text { Julgamento Passo a } \\
\text { Passo }\end{array}$ \\
\hline $\begin{array}{l}3 \text { - Before you make your final selection of a } \\
\text { product, you would: Seek a lot of inform ation } \\
\text { about each product }\end{array}$ & $\begin{array}{l}3 \text { - Antes de tomar a decisão final sobre um } \\
\text { produto, eu: Procuro muita inform ação sobre cada } \\
\text { produto. }\end{array}$ & $\begin{array}{l}\text { Julgamento Passo a } \\
\text { Passo }\end{array}$ \\
\hline $\begin{array}{l}4 \text { - Before you make your final selection of a } \\
\text { product, you would: Think a lot ab out yourself } \\
\text { as a user of the product (i.e.: How you would } \\
\text { look, feel, etc) }\end{array}$ & $\begin{array}{l}4 \text { - A ntes de tomar a decião final sobre um } \\
\text { produto, eu: Penso muito em mim mesmo como } \\
\text { um usuário do produto (como eu ficaria, como me } \\
\text { sentiria, etc). }\end{array}$ & Julgamento A fetivo \\
\hline $\begin{array}{l}5 \text { - I believe in ex } \\
\text { being impulsive }\end{array}$ & $\begin{array}{l}5 \text { - Eu acredito em exercitar o au to-controle e não } \\
\text { ser impulsivo quando decido sobre um produto. }\end{array}$ & $\begin{array}{l}\text { Julgament } \\
\text { Passo }\end{array}$ \\
\hline $\begin{array}{l}6 \text { - I believe in making a responsib le and well- } \\
\text { considered decision }\end{array}$ & $\begin{array}{l}6 \text { - Eu acredito em tomar uma decisão } \\
\text { responsável muito ponderada. }\end{array}$ & $\begin{array}{l}\text { Julgamento Passo a } \\
\text { Passo }\end{array}$ \\
\hline $\begin{array}{l}7 \text { - I believe in selecting a produc } \\
\text { careful examination of all its feat }\end{array}$ & $\begin{array}{l}7 \text { - Eu acredito em selecionar um produto com } \\
\text { base no exame cuidadoso de todas as suas } \\
\text { caracteristicas. }\end{array}$ & $\begin{array}{l}\text { Julgamento Passo a } \\
\text { Passo }\end{array}$ \\
\hline 8 - I prefer a pro & $\begin{array}{l}8 \text { - Eu prefiro um produto que reflita quem eu } \\
\text { sou. }\end{array}$ & Siznificado Simbólico \\
\hline $\begin{array}{l}9 \text { - I think it is important to select the most } \\
\text { practical product. }\end{array}$ & $\begin{array}{l}9 \text { - Eu acho que é importante selecionar o produ to } \\
\text { mais prático. }\end{array}$ & Ho U \\
\hline $\begin{array}{l}10 \text { - The image a product portrays is na } \\
\text { important part of mydecision whether or not } \\
\text { to buy it }\end{array}$ & $\begin{array}{l}10 \text { - A imagem que um produto possui é uma } \\
\text { parte importante da minha decisão em compra-lo } \\
\text { ou não. }\end{array}$ & Sign \\
\hline $\begin{array}{l}11 \text { - The instant I see a product I know if I like } \\
\text { it. }\end{array}$ & $\begin{array}{l}\text { ll - Ho instante que eu vejo um produto eu já sei } \\
\text { que eu gosto dele. }\end{array}$ & Julg \\
\hline $\begin{array}{l}12 \text { - To what extend would you want your } \\
\text { chosen product to be: A product that you can } \\
\text { proudly display }\end{array}$ & $\begin{array}{l}12 \text { - A té que ponto você iria querer que o produto } \\
\text { que você escolheu fosse algo que você pode exibir } \\
\text { com orgulho. }\end{array}$ & ico \\
\hline $\begin{array}{l}13 \text { - To what extend would you w } \\
\text { chosen product to be: In fashion o }\end{array}$ & $\begin{array}{l}13 \text { - A té que ponto você iria querer que o produto } \\
\text { que você escolheu fosse um produto que está na } \\
\text { moda. }\end{array}$ & \\
\hline $\begin{array}{l}14 \text { - To what ex } \\
\text { chosen product }\end{array}$ & $\begin{array}{l}14 \text { - A té que ponto você iria querer que o produ to } \\
\text { que você escolheu fosse um produ to reconhecido } \\
\text { como sendo caro. }\end{array}$ & lico \\
\hline $\begin{array}{l}15 \text { - To what extend would you want your } \\
\text { chosen product to be: Most com patible with } \\
\text { the image you have of yourself }\end{array}$ & $\begin{array}{l}\text { 15 - A té que ponto você iria querer que o produto } \\
\text { que rocê escolheu fosse um produto muito } \\
\text { compatível com a imagem que rocê tem de si } \\
\text { mesmo. }\end{array}$ & $\mathrm{Si}$ \\
\hline $\begin{array}{l}16 \text { - To what extend would you want your } \\
\text { chosen product to be: Something that puts you } \\
\text { in a good mood when you use it }\end{array}$ & $\begin{array}{l}\text { l6 - A té que ponto você iria querer que o produ to } \\
\text { que você escolheu fosse algo que deixasse você de } \\
\text { bom humor quando o usasse. }\end{array}$ & Julgamento A fetivo \\
\hline $\begin{array}{l}17 \text { - To what extend would you want your } \\
\text { chosen product to be: Something that feels } \\
\text { pleasent to your senses (i.e. sight, feel, etc.) }\end{array}$ & $\begin{array}{l}17 \text { - A té que ponto você iria querer que o produ to } \\
\text { que você escolheu fosse algo agradável para seus } \\
\text { sentidos (ex.: olfato, visão, etc.) }\end{array}$ & ivo \\
\hline $\begin{array}{l}18 \text { - Usually my selection of a product is b ased } \\
\text { on a gut feeling. }\end{array}$ & $\begin{array}{l}18 \text { - Hormalmente, eu seleciono um produ to } \\
\text { baseadoem um sentimento ou impulso intemo. }\end{array}$ & mento A fetivo \\
\hline $\begin{array}{l}19 \text { - When deciding on whether or not to buy a } \\
\text { product I think about how useful it will be }\end{array}$ & $\begin{array}{l}19 \text { - Quando eu estou decidindo sobre a compra } \\
\text { ou não de um produto, eu penso na utilidade dele. }\end{array}$ & $\mathrm{Si}_{\mathrm{S}}$ \\
\hline
\end{tabular}


Embora tenha sido aplicada no Brasil e submetida ao processo de tradução-retradução, a escala ainda não foi validada empiricamente para uma realidade brasileira. Talvez, tal fato se deva às dificuldades associadas à validação de instrumentos para culturas diferentes. Conforme apontado por Smith e Bond (1999), ao se realizarem estudos transculturais, vários fatores podem influenciar negativamente na adaptação de escalas de uma cultura para outra. Com isso, muitas vezes um estudo pode ser replicado (ou falhar na replicação) sem que se saiba ao certo se o resultado decorreu das similaridades ou diferenças entre os dois grupos estudados, ou se fora decorrente de alguma variável não controlada adequadamente. Dentre estas variáveis, podemos citar:

- Tradução. Muitas vezes é necessária a tradução de um instrumento para aplicação do mesmo em diferentes culturas. Escalas mal traduzidas podem gerar incompreensão, item ambíguo ou item cujo significado difere do original. A técnica comumente aceita para diminuir tais problemas é a traduçãoretradução, descrita por Brislin (1980) e Brislin, Lonner e Thorndike (1973).

- Manipulação de variáveis. Instrumentos em psicologia social tendem a utilizar a manipulação de um construto. A afirmação "Você negocia como um judeu” pode ser interpretada de forma diferente em distintas culturas. Para sanar este problema, faz-se necessária a colaboração de pessoas nativas do país em que o instrumento está sendo adaptado e que sejam também familiarizadas com a cultura do país de origem do instrumento.

- Sujeitos. Os sujeitos, que a princípio possuem as mesmas características, podem diferir bastante entre si por razões culturais. Estudantes do ensino secundário em países ocidentais desenvolvidos possuem perfil e características diferentes de estudantes do mesmo grau de certos países da África. Essa diferença pode decorrer de fatores culturais ou mesmo socioeconômicos. Para solucionar tal dificuldade, é necessário observar a experiência do sujeito ou mesmo estudar um processo que seja menos influenciado pela cultura.

Tendo sido apresentados os conceitos, juntamente com as dificuldades metodológicas, cabem questões. A estrutura proposta por Allen se repete na cultura brasileira? A escala serve para medir o processo de julgamento e significado do produto no Brasil? Para responder a estas perguntas, foi realizada a pesquisa descrita a seguir.

\section{Método}

A amostra foi composta de 588 participantes, sendo 50,7\% do sexo feminino. A maioria dos participantes (55,1\%) possui ensino secundário completo. A média de idade foi de 25,67 anos $(D P=8,64)$.

Os questionários foram aplicados em universidades e faculdades do Distrito Federal, tanto em salas de aula, quanto em locais de grande movimentação (pátios, cantinas, etc.). Nas aplicações em sala de aula, foram entregues seis questionários a cada aluno, e lhes foi pedido que, após responder a um deles, aplicasse os outros cinco instrumentos a indivídu- os fora da universidade. Desta forma, foi possível obter a resposta de participantes da pesquisa que não eram estudantes universitários. Nas aplicações em universidades e faculdades, os instrumentos foram aplicados individualmente, abordando pessoas que se encontravam sozinhas ou em grupos, sendo solicitado que respondessem o instrumento individualmente. Os alunos que aplicaram os instrumentos a terceiros o fizeram após receberem treinamento para aplicação pelos pesquisadores. Com isso, houve uma uniformidade no recrutamento dos participantes e na aplicação do instrumento.

Todos os participantes responderam avaliando o quanto concordavam com cada item de acordo com uma escala tipo Likert que variava de 1 a 7 . O número 1 indicava que a pessoa discorda totalmente, o número 7 indicava que a pessoa concorda totalmente, e o número 4 (ponto médio), indica que a pessoa nem concorda, nem discorda.

\section{Resultados}

As respostas aos instrumentos foram submetidas à análise fatorial pelo método Principal Axis Factoring (PAF) com rotação oblíqua, utilizando o critério de eingenvalues superiores a 3. O índice de fatorabilidade, $\mathrm{KMO}$, da escala foi de 0,74 . Os resultados destas análises indicaram dois fatores: o primeiro possui variância explicada de 18,33 e coeficiente de confiabilidade (Alfa de Cronbach) de 0,76, sendo composto pelos itens dos fatores originais Julgamento Passo-a-passo e Significado Utilitário, acrescido do item 4, totalizando 9 itens. O segundo explica 15,97\% da variância e apresenta alfa de 0,73. É composto pelos itens dos fatores originais Julgamento Afetivo e Significado Simbólico, com exceção do item 4, totalizando 10 itens. Após as análises, todos os 19 itens iniciais permaneceram na escala.

A Tabela 2 apresenta as cargas fatoriais dos itens por fator. Dos cinco itens que possuem melhores cargas fatoriais, quatro compõem o fator 1 . São eles: item 2 - "Antes de você tomar a decisão final sobre um produto, você: Considera os prós e contras sobre cada produto" -, que obteve carga de 0,72; item 6 - “Eu acredito em tomar uma decisão responsável muito ponderada” -, que obteve carga de 0,70; item 7 - "Eu acredito em selecionar um produto com base no exame cuidadoso de todas as suas características” -, que obteve carga de 0,64; e item 3 - "Antes de tomar a decisão final sobre um produto, eu: Procuro muita informação sobre cada produto” -, que obteve carga de 0,61. O item 16 - “Até que ponto você iria querer que o produto que você escolheu fosse algo que deixasse você de bom humor quando o usasse" -, foi o que obteve melhor carga fatorial para o fator 2. Vale notar que a matriz de correlação dos fatores apresentou uma correlação negativa de 0,52 entre os fatores 1 e 2 . A Tabela 2 apresenta também as médias, desvios-padrões por item e por fator. $\mathrm{O}$ item que possui o maior desvio-padrão $(D P=1,94)$ e que, portanto, indica uma melhor distribuição de respostas na escala, foi o item 12: “Até que ponto você iria querer que o produto que você escolheu fosse algo que você pode exibir com orgulho". 
Tabela 2

Cargas fatoriais, médias e desvios padrões por item e fator

\begin{tabular}{|c|c|c|c|c|}
\hline Item & $\begin{array}{c}\text { Fator } 1 \\
\text { Racional }\end{array}$ & $\begin{array}{l}\text { Fator } 2 \\
\text { Emotivo }\end{array}$ & Média & $\begin{array}{l}\text { Desvio } \\
\text { Padrão }\end{array}$ \\
\hline 1. Eu acredito em ser lógico e racional quando decido sobre um produto. & 0,53 & & 5,35 & 1,44 \\
\hline $\begin{array}{l}\text { 2. Antes de você tomar a decisão final sobre um produto, você: Considera os } \\
\text { prós e contras sobre cada produto. }\end{array}$ & 0,72 & & 5,72 & 1,34 \\
\hline $\begin{array}{l}\text { 3. Antes de tomar a decisão final sobre um produto, eu: Procuro muita informa- } \\
\text { ção sobre cada produto. }\end{array}$ & 0,61 & & 5,26 & 1,45 \\
\hline $\begin{array}{l}\text { 4. Antes de tomar a decisão final sobre um produto, eu: Penso muito em mim } \\
\text { mesmo como um usuário do produto (como eu ficaria, como me sentiria, etc). } \\
\text { 5. Eu acredito em exercitar o auto-controle e não ser impulsivo quando decido }\end{array}$ & 0,40 & & 5,95 & 1,23 \\
\hline sobre um produto. & 0,61 & & 4,91 & 1,7 \\
\hline 6. Eu acredito em tomar uma decisão responsável muito ponderada & 0,70 & & 5,28 & 1,44 \\
\hline $\begin{array}{l}\text { 7. Eu acredito em selecionar um produto com base no exame cuidadoso de todas } \\
\text { as suas características. }\end{array}$ & 0,64 & & 5,17 & 1,43 \\
\hline 8. Eu prefiro um produto que reflita quem eu sou. & & 0,38 & 5,42 & 1,45 \\
\hline 9. Eu acho que é importante selecionar o produto mais prático. & 0,38 & & 5,31 & 1,5 \\
\hline $\begin{array}{l}\text { 10. A imagem apresentada por um produto é parte importante da minha decisão } \\
\text { em comprá-lo ou não }\end{array}$ & & 0,56 & 5,35 & 1,52 \\
\hline 11. No instante que eu vejo um produto eu já sei que eu gosto dele & & 0,45 & 4,78 & 1,77 \\
\hline $\begin{array}{l}\text { 12. Até que ponto você iria querer que o produto que você escolheu fosse algo } \\
\text { que você pode exibir com orgulho. }\end{array}$ & & 0,59 & 4,98 & 1,94 \\
\hline $\begin{array}{l}\text { 13. Até que ponto você iria querer que o produto que você escolheu fosse um } \\
\text { produto que está na moda. }\end{array}$ & & 0,57 & 4,4 & 1,63 \\
\hline $\begin{array}{l}\text { 14. Até que ponto você iria querer que o produto que você escolheu fosse um } \\
\text { produto reconhecido como sendo caro }\end{array}$ & & 0,54 & 3,56 & 1,78 \\
\hline $\begin{array}{l}\text { 15. Até que ponto você iria querer que o produto que você escolheu fosse um } \\
\text { produto muito compatível com a imagem que você tem de si mesmo. } \\
\text { 16. Até que ponto você iria querer que o produto que você escolheu fosse algo }\end{array}$ & & 0,54 & 5,38 & 1,52 \\
\hline que deixasse você de bom humor quando o usasse. & & 0,62 & 6,27 & 1,01 \\
\hline $\begin{array}{l}\text { 17. Até que ponto você iria querer que o produto que você escolheu fosse um } \\
\text { produto que fosse agradável aos seus sentidos (ex.: olfato, visão, etc.) }\end{array}$ & & 0,58 & 6,1 & 1,12 \\
\hline $\begin{array}{l}\text { 18. Normalmente, eu seleciono um produto baseado em um sentimento ou } \\
\text { impulso interno }\end{array}$ & & 0,57 & 4,18 & 1,84 \\
\hline $\begin{array}{l}\text { 19. Quando eu estou decidindo sobre a compra ou não de um produto, eu penso } \\
\text { na utilidade dele. }\end{array}$ & 0,58 & & 5,84 & 1,23 \\
\hline Média & 5,44 & 5,10 & & \\
\hline (Desvio Padrão) & $(0,83)$ & $(0,83)$ & & \\
\hline \% Variância Explicada & 18,33 & 15,97 & & \\
\hline Alfa de Cronbach & 0,76 & 0,73 & & \\
\hline
\end{tabular}

\section{Discussão}

O modelo proposto por Allen (1997; 2000; 2001), apresentado na Figura 1, abrange quatro fatores distintos, sendo dois deles relativos ao processo de julgamento do produto e dois relativos ao processo de atribuição de significado. Conforme visto anteriormente, estes fatores são relacionados. O Julgamento Afetivo (julgar emocionalmente, através de atributos abstratos) é o processo que origina a atribuição de significado simbólico a um produto. O Julgamento Passo-apasso (julgar racionalmente, tendo como base atributos do produto) origina a atribuição de significado utilitário a um produto. $\mathrm{O}$ autor evidencia a relação entre os fatores em sua teoria, no entanto, procura deixar clara a diferença entre os dois processos. O processo de julgamento ocorre previamente ao de atribuição de significado, por isso os mesmos deveriam estar em fatores distintos. Apesar de os coeficientes alfas dos fatores estarem razoavelmente adequados (Tabachnick
\& Fidell, 1996), estando em 0,76 (Fator 1) e 0,73 (Fator 2), o resultado encontrado demonstra uma contradição teórica que deve ser explicada.

Os resultados demonstram que os itens relativos ao processo de julgamento passo-a-passo e significado utilitário se uniram em um único fator (Fator 1) que foi denominado de Julgamento e Significado Racional. Os itens relativos ao processo de julgamento afetivo e significado simbólico uniramse, formando um único fator (Fator 2), chamado de Julgamento e Significado Emotivo. Resultado semelhante foi encontrado em outras pesquisas realizadas com amostras brasileiras (e.g., Allen \& Torres, 2006; Torres \& Allen, 2006). Por exemplo, no estudo de Torres e Allen (no prelo), também foram encontrados dois fatores, com alfas menos confiáveis 0,75 (Racional) e 0,69 (Emotivo). Esta mesma nomenclatura foi apresentada em Nepomuceno e Torres (2003), que teve estudo baseado em uma amostra de estudantes universitários. Interessante notar que em todos esses estudos, quando amos- 
tras brasileiras foram utilizadas, houve o aglutinamento dos quatro fatores descritos na literatura em apenas dois fatores. Além disso, sempre se observa uma união no mesmo sentido, ou seja, os fatores previstos como de Julgamento se unem aos supostos fatores de Significado (Passo-a-Passo com Utilitário, e Afetivo com Simbólico). Uma possível interpretação para a recorrente constatação dessa estrutura bi-fatorial pode estar nos próprios valores culturais dos brasileiros. Conforme apresentado inicialmente por Hofstede (1980), e constatado em diversos outros estudos (e.g., Dessen \& Torres, 2002; Nogueira, 2001), o coletivismo é uma característica marcante dos brasileiros. Como coletivistas, os brasileiros não tenderiam a processar informações de maneira fragmentada, o que foi chamado por Triandis (1995) como uma orientação "racional” das informações. Ao invés disso, a ênfase está na relação subjacente ao processo (chamado de orientação “relacional” pelo autor). Talvez, tal característica cultural faça com que haja a percepção de indiferenciação entre julgamento e significado, resultando em fatores agregados. Pessoas de valores individualistas, entretanto, devido a sua orientação racional, identificam e diferenciam com mais clareza os processos envolvidos nos julgamentos (Passo-a-Passo e Afetivo) da atribuição de significado (Utilitário e Simbólico), quando comparados aos coletivistas.

Vale a pena notar ainda que as médias dos fatores encontradas apresentam-se acima do ponto médio da escala (i.e., 5,44 para o Fator 1 e 5,10 para o Fator 2). Conforme indicado por Smith e Bond (1999), indivíduos de culturas coletivistas tenderiam a apresentar um erro ou viés de resposta, qual seja, responder em torno do ponto médio de escalas de resposta (centralidade de resposta). Dentre outros motivos, a interpretação para tal tendência estaria relacionada à manutenção de face (Singelis, 1995), mecanismo comum nesse tipo de cultura. Para os autores, a ocorrência desse padrão de resposta exige a correção intra-sujeito dos escores, para que assim, possa haver representatividade dos dados. Ao observarmos uma resposta média acima do que seria esperado para um viés de resposta coletivista, sugere-se que estamos na verdade observando a validade emic da escala, pois, como afirma Triandis (1995), instrumentos com validade emic apresentam uma redução em vieses de resposta como a tendência à centralidade acima discutida.

Em relação ao estudo de Nepomuceno e Torres (2003), demonstrou-se que os resultados foram semelhantes aos do presente estudo, o que indica que mesmo para estratégias de aplicação diferentes, os resultados têm-se mantido coerentes. Naquela pesquisa, apenas um item comportou-se de maneira significativamente diferente. Na versão original do instrumento e também no estudo de Nepomuceno e Torres, o Item 4 compôs um fator relacionado a um julgamento afetivo. No entanto, as análises da presente pesquisa indicam que este item compõe o fator Julgamento e Significado Racional. A redação do item é que: "Antes de tomar a decisão final sobre um produto, eu: Penso muito em mim mesmo como um usuário do produto (como eu ficaria, como me sentiria, etc.)”. A análise do resultado e do item indica que o mesmo não está claro. Se, neste estudo, o item estivesse compondo o fator Julgamento e Significado Emotivo, seria plausível concluir que os participantes estariam julgando o produto a partir de critérios emocionais, levando em conta aspectos subjetivos e pessoais para a escolha do produto. No entanto, uma vez que o item compôs o fator oposto, pode-se concluir que ele descreve um processo de escolha ponderada que segue critérios coerentes, mas que trata sobre um aspecto subjetivo funcionando, dessa forma, como um processo racional sobre uma variável subjetiva. Vale lembrar que os resultados do presente estudo são mais confiáveis, uma vez que possuem uma amostra mais heterogênea.

Várias razões podem ser apontadas para explicar a existência de dois fatores na realidade brasileira. Segundo Pasquali (2003), a redação de um item deve ser clara e objetiva para que diminua ambigüidades e seja fiel àquilo que se propõe a medir. Analisando os itens propostos e traduzidos da escala, verifica-se que eles possuem problemas de compreensão. Por exemplo, o Item 1 possui a seguinte redação: "Eu acredito em ser lógico e racional quando decido sobre um produto”. Este item possui duas idéias principais: ser lógico ao decidir sobre um produto e ser racional ao decidir sobre um produto. Apesar de serem sinônimos, as duas palavras podem possuir significados diferentes, o que causaria a medição de dois fatores diferentes em um mesmo item. As pessoas tendem a compreender a palavra racional como aquilo que advém da razão ou do raciocínio, enquanto a palavra lógica é ampla e pode exprimir tanto uma lógica racional, quanto uma lógica imposta pelas emoções. Ocorrendo este último caso, fica claro que, para alguns participantes, o item pode ficar de difícil compreensão.

Outros exemplos de dificuldade de compreensão estão nos itens 12 a 17. Todos eles começam com o texto "Até que ponto você iria querer que o produto que você escolheu...”. No entanto, semanticamente estes itens não estão coerentes com a escala. Nas instruções é solicitado aos participantes que respondam em uma escala do tipo Likert de concordância, que varia entre discorda totalmente e concorda totalmente. Com isso, o item pode induzir uma dificuldade de compreensão em vários dos respondentes, já que a escala a ser utilizada para resposta não está adequadamente apropriada à redação destes itens.

Ainda segundo Pasquali (2003), itens curtos e objetivos tendem a diminuir ambigüidades e aumentar seu poder de discriminação (o quanto ele consegue diferenciar os traços medidos). Geralmente, itens longos possuem muitos conceitos, exigindo um maior esforço cognitivo dos sujeitos, aumentando por sua vez a possibilidade de ambigüidade ou incompreensão. A escala proposta possui itens longos como o item 4, já apresentado. A redação do mesmo poderia ser simplificada, para que o respondente pudesse compreender mais facilmente o que está sendo solicitado.

Há de se lembrar também que o inventário original possui apenas 19 itens para medir quatro fatores, o que aparentemente é uma pequena quantidade de itens para grande quantidade de traços a se medir. Estudos recentes apresentam 
quantidade superior de itens. Por exemplo, Araújo, Moreira e Assis (2003) realizaram um estudo sobre o significado de responsabilidade social de empresas privadas para o consumidor que resultou em um instrumento com 83 itens. Este estudo apresenta um número excepcionalmente elevado de itens, mesmo assim a diferença é significativa em relação ao instrumento de Allen (1997). Outros estudos que confirmam essa crítica são o de Mittal (1988), que utilizou uma escala com 23 itens para estudar o papel do modo afetivo de escolha para produtos expressivos; o de Richins (1994), que apresentou 23 itens para estudar o significado público e privado das posses; e o de Triki e Wesson (2002), que desenvolveu uma escala com 15 itens para medir a percepção instrumental de um produto. Essa quantidade relativamente pequena de itens no instrumento de Allen (1997) deve-se, provavelmente, à busca do autor em criar uma escala que seja fidedigna e também de prática aplicação e aceitação no mercado.

É interessante observar que Richins (1994) apresenta a importância do significado privado das posses. Allen (1997; 2000; 2001), em vários de seus estudos, também aponta a importância deste fator. No entanto, na criação de sua escala, o autor não inclui itens que medem o mesmo, centrando o fator Significado Simbólico apenas ao aspecto público do mesmo. Com isso, o instrumento fica aquém do que poderia ser.

Além de todos estes problemas discutidos, há ainda os já apresentados, relativos às dificuldades de adaptação de um instrumento de uma cultura para outra (Smith \& Bond, 1999). Dentre as dificuldades apresentadas na Introdução, uma que foi encontrada é relativa à "manipulação de variáveis”, ou seja, maneiras diferentes com que mesmas expressões podem ser compreendidas em diferentes culturas. Conforme pode ser visto na Tabela 1, o item 18 possui a expressão gut feeling, que foi traduzida como impulso interno. No entanto, esta expressão é de difícil compreensão na cultura brasileira, já que pode ser compreendida de várias maneiras. Impulso interno é entendido desde impulso fisiológico até impulso de natureza psicológica. Apesar desta dificuldade, o item apresentou carga fatorial relativamente boa $(0,57)$. O grande desvio-padrão do item $(D P=1,84)$ pode ser em decorrência das diversas compreensões dos participantes. Há de se realizar entrevistas, em pesquisas futuras, para que se possa afirmar com clareza.

Os diversos problemas psicométricos da escala podem explicar a indistinção dos fatores, tal como previsto na teoria. Conforme demonstrado, o processo de julgamento ocorre previamente à atribuição de significado. No entanto, pelos vários motivos apontados, o instrumento não consegue realizar essa distinção. Outra possibilidade de explicação decorre da tentativa de medir dois processos diferentes (julgamento e atribuição de significado) em um único instrumento. Conforme dito, o julgamento passo-a-passo relaciona-se com o significado utilitário e o julgamento afetivo relaciona-se com o significado simbólico. Estes processos diferenciam-se basicamente pelo momento em que ocorrem. Sendo assim, é possível que os conceitos tenham se misturado, uma vez que essa diferença temporal não fica clara para o respondente.
Para responder às questões de pesquisa (A estrutura proposta por Allen se repete na cultura brasileira? A escala serve para medir o processo de julgamento e significado do produto no Brasil?) deve-se ainda considerar as limitações relativas à composição da amostra. A quantidade de sujeitos encontra-se adequada para o número de itens (10 sujeitos por item), no entanto por ser uma amostra composta de participantes de Brasília, torna-se obviamente impossível generalizar os resultados para toda realidade brasileira. No entanto, deve-se lembrar as características dos habitantes de Brasília; cidade que possui fundação relativamente recente e que é composta por habitantes de várias regiões e cidades brasileiras. Com isso, os resultados demonstraram não apenas as necessidades de aprimoramentos discutidos anteriormente, mas também argumentos iniciais que possibilitarão uma generalização para a realidade nacional, condicionados pela realização de futuras pesquisas.

Finalmente, vale ressaltar que o modelo proposto por Allen parece adequado e está embasado em vários estudos recentes (Torres \& Allen, no prelo). No entanto, o presente estudo demonstra que o instrumento não está adequado para aplicação na realidade brasileira, necessitando de uma adaptação para nossa cultura. Estudos com este fim estão sendo realizados no presente momento, para que um instrumento confiável possa ser utilizado na realidade nacional, tendo também como objetivo a confirmação da teoria proposta.

\section{Referências}

Allen, M. W. (1997). The direct and indirect influences of human values on consumers choices. Tese de Doutorado não-publicada, Universidade de Vitória, Wellignton.

Allen, M. W. (2000). The attribute-mediation and product meaning approaches to the influences of human values on consumer choices. Advances in Psychology Research, 1, 31-76.

Allen, M. W. (2001). A practical method for uncovering the direct and indirect relationships between human values and consumer purchases. Journal of Consumer Marketing, 18(2), 102-120.

Allen, M. W., \& Ng, S. H. (1999). The direct and indirect influence of human values on product ownership. Journal of Economic Psychology, 20(1), 5-39.

Allen, M. W., \& Torres, C. V. (2006). Food symbolism and consumer choice in Brazil. In S. Gonzalez \& D. Luna (Orgs.), Latin American advances in consumer research (pp. 32-45). Monterey, México: Association for Consumer Research.

Araújo, M. M., Moreira, S. A., \& Assis, G. J. A. (2003). Significado de responsabilidade social de empresas privadas para o consumidor [Resumo]. In Sociedade Brasileira de Psicologia (Org.), XXXIII Reunião Anual de Psicologia. Resumos (p. 259). Belo Horizonte: Autor.

Belk, R. W. (1988). Possessions and the extended self. Journal of Consumer Research, 15(2), 139-168.

Brislin, R. W. (1980). Translation and content analysis of oral and written materials. In H. C. Triandis \& J. W. Berry (Orgs.), Handbook of crosscultural psychology (Vol. 4; pp. 398-444). Boston: Allyn \& Bacon.

Brislin, R. W., Lonner, W., \& Thorndike, R. M. (1973). Cross-cultural research methods. Nova York: Wiley.

Dessen, M. A., \& Torres, C. V. (2002). Family and socialization factors in Brazil: an overview. In W. J. Lonner, D. L. Dinnel, S. A. Haynes and D. N. Sattler (Orgs.), In online readings in Psychology and culture (Vol. 13, pp. 1-11). Western Washington University; Center for Cross-Cultural Research. 
Engel, J. F., Blackwell, R. D., Miniard, P. W. (2000). Comportamento do consumidor. São Paulo: LTC.

Fishbein, M. (1963). An investigation of the relationships between beliefs about the object and the attitude toward that object. Human Relations, (16), 233-240.

Fiske, S. T., \& Pavelchack, M. A. (1986). Category-based versus piecemealbased affective responses: developments in schema-triggered affect. Journal of Economic Psychology, 20(1), 5-39.

Healey, J., Lutz. R., \& Healey, G. (1974). Operationalizing the Katz functional theory of attitudes: initial findings (Center for Marketing Studies Working Paper $\mathrm{n}^{\mathrm{o}}$ 17). Los Angeles: University of California Press.

Heider, F. (1967). Attitudes and cognitive organization. In M. Fishbein (Org), Readings in attitude theory and measurement (pp. 39-41). Nova York: Wiley.

Hofstede, G. (1980). Culture's consequences. Beverly Hills: Sage.

James, W. (1890). The principles of Psychology (Vol. 1). Nova York: Dover.

Kahle, L. R., \& Kennedy, P. (1988). Using the List of Values (LOV) to understand consumers. The Journal of Services Marketing, 2(4), 49-56.

Katz, D. (1960). The functional approach to the study of attitudes. Journal of Marketing Research, 15, 576-587.

Kotler, P. (1984). Marketing management: analysis, planning and control. New Jersey: Prantice-Hall.

Locander, W. B., \& Spivey, W. A. (1978). A functional approach to attitude measurement. Journal of Marketing Research, 15, 576-587.

Marx, K. (2003). Manuscritos econômico-filosóficos. São Paulo: Martin Claret. (Texto original publicado em 1844)

McCracken, G. (1987). Culture and consumption among the elderly: three research objectives in an emerging field. Aging and Society, 7(2), 203-224.

Mittal, B. (1988). The role of affective choice mode in the consumer purchase of expressive products. Journal of Economic Psychology, 9, 499-524.

Nepomuceno, M. V., \& Torres, C. V. (2003). Tradução e validação de uma Escala de Significado e Julgamento do Produto [Resumo]. In Sociedade Brasileira de Psicologia (Org.), XXXIII Reunião de Psicologia. Resumos (p. 357). Belo Horizonte: Autor.

Nogueira, A. H. A. (2001). Padrões culturais e normas para comportamentos de liderança: um estudo comparativo entre empregados de empresas de previ- dência privada do Brasil e dos EUA. Dissertação de Mestrado não-publicada, Universidade de Brasília, Brasília.

Torres, C. V., \& Allen, M. W. (2006). Consumer behavior and cultural values: examining differences in consumer decision making for holiday destination in Australia and Brazil [Resumo]. In International Association for Cross-Cultural Psychology (Org.), 18th International Congress (p.144). Spetses: Autor.

Torres, C. V., \& Allen, M. W. (no prelo). Human values, product meaning, and consumption in Brazil. Journal of Organizational Behavior.

Triandis, H. C. (1995). Individualism and collectivism. Bouder: Westview.

Pasquali, L. (2003). Psicometria: Teoria dos testes na Psicologia e na Educação. Petrópolis: Vozes.

Pratkanis, A. R., Breckler, S. J., \& Greenwald, A. G. (1989). Attitude structure and function. Hillsdale: Lawrence Erlbaum.

Richins, M. L. (1994). Valuing things: the public and private meanings of possessions. Journal of Consumer Research, 21, 504-521.

Schwartz, S. H., \& Bilsky, W. (1987). Toward a universal psychological structure of human values. Journal of Personality and Social Psychology, 53, 550-562.

Schwartz, S. H., \& Bilsky, W. (1990). Toward a theory of the universal content and structure of values: extensions and cross-cultural replications. Journal of Personality and Social Psychology, 58, 878-891.

Smith, P. B., \& Bond, M. H. (1999). Social Psychology across cultures. Boston: Allyn \& Bacon.

Tabachnick, B., \& Fidell, L. S. (1996). Using multivariate statistics. Nova York: Harper Collins.

Tamayo, A. (1981). EFA: Escala Fatorial de Autoconceito. Arquivos Brasileiros de Psicologia, 33(4), 87-102.

Tamayo, A., \& Schwartz, S. H. (1993). Estrutura motivacional dos valores humanos. Psicologia: Teoria e Pesquisa, 9, 329-348.

Thaler, R. (1985). Mental accounting and consumer choice. Marketing Science, 4, 199-214.

Triki, A., \& Wesson, D. (2002). Perceived product instrumentality: the process of scale purification and validation. Journal of Consumer Behaviour, 1(4), 379-399.

Weber, M. (1991). Economia e sociedade. Fundamentos da Sociologia Compreensiva. Brasília: Editora da UnB. (Texto Original publicado em 1922)

Marcelo Vinhal Nepomuceno é mestre em Psicologia pela Universidade de Brasília. Endereço para correspondência: Universidade de Brasília; Instituto de Psicologia; Laboratório de Psicologia Social e Organizacional; Campus Universitário Darcy Ribeiro; Brasília, DF; CEP: 70.910-900. Tel.: (61) 307-2625 (r. 223) ou (61) 577-3194.E-mail:marcelo_cripta@yahoo.com.br ou slockking@hotmail.com

Cláudio Vaz Torres, doutor em Psicologia Organizacional pela California School of Professional Psychology (Estados Unidos), é professor no Instituto de Psicologia, Universidade de Brasília. E-mail: claudpsius@aol.com ou ctorres@unb.br 